\title{
Complicated Diverticulitis
}

\author{
Case Report
}

\section{W.A. Bemelman}

Department of Surgery, Academic Medical Center, Amsterdam, The Netherlands

\section{Key Words}

Colorectal - Diverticulitis - Hartmann's procedure . Perforation

\section{Case Report}

A 51-year-old female was admitted with abdominal pain that had started in the left lower quadrant. Besides nephrolithiasis, her medical history was uneventful. She was moderately sick and had $38.4^{\circ} \mathrm{C}$ fever. Physical examination of the abdomen revealed signs of diffuse peritonitis. A plain abdominal X-ray showed free air and distended small bowel loops. Explorative laparotomy was done and a diffuse purulent peritonitis was found due to a perforated diverticulitis.

\section{Question}

What kind of operation would you perform?

A Hartmann's procedure

Audience's response

B Sigmoidectomy and primary anastomosis $45 \%$

C Sigmoidectomy and peroperative lavage and anastomosis

$32 \%$

$7 \%$

D Sigmoidectomy and anastomosis and loop ileostomy

$10 \%$

E Sigmoidectomy and peroperative lavage and anastomosis and loop ileostomy

\section{Comment}

No evidence exists what operation is best for perforated diverticulitis. Most surgeons would advise Hartmann's procedure for two reasons. First the procedure is considered the least extensive operation and can easily be done by the resident on call. This misconception is probably the cause of a high incidence of stoma-related complications (retraction, ischemia). A good Hartmann's operation, namely creation of a vital and traction-free colostomy, often requires mobilization of the left flexure. This requires considerable technical skill and experience. Secondly the proponents of a Hartmann's procedure fear the adverse events of anastomotic leakage in case of primary restoration of the continuity [1-6].

Advocates of resection and primary anastomosis disapprove of Hartmann's procedure because $30-40 \%$ of the colostomies will not be reversed. Reversal is associated with considerable morbidity and even mortality. Even so, it is questioned whether anastomotic leakage after resection and anastomosis for sigmoid perforation is an important cause of death. Most patients die of the consequences of generalized peritonitis due to the sigmoid perforation. So it is still at the discretion of the operating surgeon to decide what operation is best for the particular patient.

The grade of peritonitis classified according to Hinchey (table 1) can be of help to determine what operation

\begin{tabular}{ll}
\hline KARGER & ( ) 2002 S. Karger AG, Basel \\
0253-4886/02/0192-0147\$18.50/0 \\
$\begin{array}{l}\text { Fax +4161306 12 34 } \\
\begin{array}{l}\text { E-Mail karger@karger.ch } \\
\text { www.karger.com }\end{array}\end{array}$ & $\begin{array}{l}\text { Accessible online at: } \\
\text { www.karger.com/journals/dsu }\end{array}$
\end{tabular}

W. A. Bemelman

Department of Surgery, Academic Medical Center Amsterdam

P.O. Box 22660

NL-1100 DD Amsterdam (The Netherlands)

Tel. +31 2056626 66, Fax +31 2069148 58, E-Mailw.a.bemelman@amc.uva.nl 
Table 1. Hinchey classification

I Diverticulitis with no or local peritonitis

II Diverticulitis with small pericolic abcess

III Diverticulitis with local purulent (a) or fecal (b) peritonitis

IV Diverticulitis with diffuse purulent (a) or fecal (b) peritonitis

is best for the patient. It can be suggested that patients with Hinchey I and II will have resection and primary anastomosis. Patients with Hinchey III and IV are probably best treated with either Hartmann's procedure or resection and primary anastomosis and fecal diversion, preferably the latter.

The rationale behind peroperative lavage is to remove the fecal load that can run through a leaking anastomosis. Only very few believe that the fecal load will cause anastomotic leakage. Peroperative lavage is an extensive procedure often requiring mobilization of both flexures, is time consuming and is associated with fecal spill. It is therefore not a very popular procedure.

\section{Case Report (Continued)}

Sigmoid resection with primary anastomosis was performed. A covering ileostomy was fashioned. Due to small bowel distension, the abdomen was closed using a Vicryl mesh. Postoperatively she was treated at the intensive care unit because of respiratory insufficiency. On the 6th postoperative day a CT scan with contrast was done that did not show any intra-abdominal abscesses. Gradually the ileus resolved and her clinical condition was good on the 12th postoperative day.

\section{Question}

What would you do now?
A Conservative treatment until full recovery
B Closure of the abdomen
C Reversal of the ileostomy
D Reversal of the ileostomy and closure of the abdomen

\begin{tabular}{|c|}
\hline Audience's \\
\hline $72 \%$ \\
\hline $15 \%$ \\
\hline $10 \%$ \\
\hline
\end{tabular}

\section{Comment}

Conservative treatment until full recovery is obviously the safest option. Sometimes if recovery is fast and ileus has resolved, it can be attempted to close the abdomen in order to avoid later surgery for incisional hernia. Early closure of a defunctioning ileostomy (within 14 days) is probably feasible and safe after elective surgery, e.g. total mesorectal excision with coloanal anastomosis. However, closure of the ileostomy does not seem wise in a patient recovering from diffuse peritonitis.

\section{Case Report (Continued)}

An attempt was done to close the abdomen. However, closure was not possible and the Vicryl mesh was reefed. On the 20th postoperative day she developed fever and respiratory insufficiency. CT scan demonstrated a perianastomotic abscess that did not allow percutaneous drainage. Laparotomy was done and a small anastomotic leakage with a confined perianastomotic abscess was found.

\section{Question}

What would you do now?
A Take down the leaking anastomosis
B Drainage of abscess $32 \%$
C Drainage of abscess and revision anastomosis

Audience's response

\section{Comment}

Since the anastomosis is deviated, simple drainage of the abscess is sufficient. Healing without stricture is often the case. Only if the anastomosis is deficient for a major part of its circumference, dismantling of the anastomosis can be necessary. Simple closure of both bowel ends with the linear stapler can be done if a Hartmann's procedure is technically difficult due to postoperative and inflammatory adhesion.

\section{Case Report (Continued)}

Recovery was uneventful. She was discharged on the 40th postoperative day. Closure of the ileostomy and repair of the incisional hernia are scheduled at a later stage. 


\section{References}

Complicated Diverticulitis
1 Gooszen AW, Tollenaar RA, Geelkerken RH, Smeets HJ, Bemelman WA, Van Schaardenburgh P, Gooszen HG: Prospective study of primary anastomosis following sigmoid resection for suspected acute complicated diverticular disease. Br J Surg 2001;88:693-697.

2 Wong WD, Wexner SD, Lowry A, Vernava A 3rd, Burnstein M, Denstman F, Fazio V, Kerner B, Moore R, Oliver G, Peters W, Ross T, Senatore P, Simmang C: Practice parameters for the treatment of sigmoid diverticulitis Supporting documentation. The Standards Task Force. The American Society of Colon and Rectal Surgeons. Dis Colon Rectum 2000; 43:290-297.

3 Ferzoco LB, Raptopoulos V, Silen W: Acute diverticulitis. N Engl J Med 1998;338:15211526.
4 Wigmore SJ, Duthie GS, Young IE, Spalding EM, Rainey JB: Restoration of intestinal continuity following Hartmann's procedure: The Lothian experience 1987-1992. Br J Surg 1995;82:27-30.

5 Santos JC Jr, Batista J, Sirimarco MT, Guimaraes AS, Levy CE: Prospective randomized trial of mechanical bowel preparation in patients undergoing elective colorectal surgery. $\mathrm{Br}$ J Surg 1994;81:1673-1676.

6 Kressner U, Antonsson J, Ejerblad S, Gerdin B Pahlman L: Intraoperative colonic lavage and primary anastomosis - An alternative to Hartmann's procedure in emergency surgery of the left colon. Eur J Surg 1994;160:287-292. 